\title{
ANALISIS KARAKTERISASI FREKUENSI DENGAN POLA LISSAJOUS
}

\author{
Barru Arrosyid \\ Prodi TeknikElektro UNPAM \\ Jln. Puspiptek Raya No 46 Buaran, Setu - Tangerang Selatan 15310 INDONESIA \\ Email: dosen00859@unpam.ac.id
}

\begin{abstract}
ABSTRAK
Saat ini, dalam dunia pendidikan elektronika diperlukan suatu modul praktikum yang dapat dengan mudah untuk menganalisa rangkaian atau komponen lebihefektif dan efisien agar meningkatkan pemahaman dan pengetahuan ilmu elektronika, dan juga dapat mempersingkat waktu praktek dan mempermudah dalam pembuatannya. Salah satumodul praktikum adalah karakterisasi frekuensi dengan pola lissajous, yang biasa digunakan untuk membanding 2 sinyal atau untuk mengetahuin nilai dari sebuah komponen yang belum diketahui frekuensi nya.Metode yang digunakan adalah dengan cara membandingkan 2 sinyal dengan cara digabungkan dalam 1 grafik sehingga akan membentuk sebuah pola. Hasil rancang bangun praktikum menunjukan bahwa modul ini dapat bekerja dengan baik. Untuk mempermudah pembacaan hasil pengukuran dan mengolah data menggunakan perangkat lunak labview, sedangkan perangkat untuk akusisi data nya menggunakan NI myDAQ. Dan juga di dukung dengan papan PCB yang digunakan untuk menempatkan komponen yang akan diukur dan di analisa.
\end{abstract}

Kata kunci :pola lissajous, labview, NI myDAQ, papan PCB

\begin{abstract}
ANALYSIS OF CHARACTERISTICS OF FREQUENCY WITH LISSAJOUS PATTERN. . Currently, in the science of electronics education is required a practical module that can be easily to analize the circuit or component of unknown components more effectively and efficiently in order to improve the understanding and knowledge of electronics, and also can shorten the practice time and simplify the making it. One of practicum modules is the frequency characterization analysis with a lissajous pattern, which is commontly used to compare 2 signals or to find out the value of unknown components frequency. The method used is to compare 2 signal by way of combined in 1 graph so that will form a pattern. The result of the practical design show that this module can work ell. To easilythe reading of measurement result and process the data value using labview software, while the device for its data acquisition using NI myDAQ. And also supported by PCB board use to place the components to be measured and analized.
\end{abstract}

Keywords:Lissajous pattern, labview, NI myDAQ, PCB board 



\section{PENDAHULUAN}

Di era sekarang ini masih banyak dijumpai alat praktikum elektronika dasar yang konvensional. Masih banyak terdapat panel-panel, indikator analog dan masih banyak menggunakan alat ukur, seperti voltmeter, ampere meter dll. Terlihat jelas bahwa efisiensi nya sangat kurang yang mana malah membuat mahasiswa sendiri kebingungan. Frekuensi adalah suatu pernyataan yang menggambarkan berapa banyak gelombang yang terjadi pada tiap detiknya dalam satuan $\mathrm{Hz}$. Didalamnya terdapat pengukuran pola lissajous. Pola Lissajous adalah sebuah penampakan pada layar osiloskop yang mencitrakan perbedaaan atau perbandingan beda fase, frekuensi dan amplitudo dari 2 gelombang inputan pada probe osiloskop. Pola lissajous tersebut juga bisa digunakan untuk mengukur frekuensi pada motor induksi 3 fasa. Dimana nantinya bisa diketahui kondisi lilitan motor induksi, apakah motor induksi tersebut masih dalam kondisi baik atau tidak.

Untuk di beberapa negara maju seperti jepang, australia, amerika dan eropa hampir semuanya sudah meninggalkan alat praktikum elektronika dasar yang konvensional tersebut. Mereka sudah menggunakan alat praktikum yang berkonsep virtual instrument. National instruments adalah salah satu perusahaan dari sekian yang mengembangkan sebuah alat yang berkonsep virtual instrument. Dan salah satu alatnya yang biasa dipakai untuk mahasiswa atau pelajar adalah $\mathrm{NI}$ my DAQ. Alat tersebut mampu untuk mengukur dan menganalisa langsung sebuah sinyal secara realtime. NI myDAQ juga mempunyai I/O yang cukup komplit sehingga cocok kalau untuk dijadikan alat praktikun elektronika dasar yang berkonsep virtual instrument. Oleh karena itu penelitian ini bertujuan supaya mampu untuk membuat alat praktikum berbasis virtual instrument dan juga bermanfaat untuk mempermudah pemahaman dalam menganalisis frekuensi dengan pola lissajous.

\section{LANDASAN TEORI}

Pola lissajous adalah sebuah penampakan pada layar osiloskop yang mencitrakan perbedaaan atau perbandingan Beda Fasa, Frekuensi dan Amplitudo dari 2 gelombang inputan pada probe osiloskop. Frekuensi adalah suatu pernyataan yang menggambarkan berapa banyak gelombang yang terjadi pada tiap detiknya dalam satuan $\mathrm{Hz}$. Bila ada tulisan 50 $\mathrm{Hz}$ berarti ada 50 gelombang yang terjadi dalam 1 detik, yang mana 1 gelombang terdiri atas 1 bukit dan 1 lembah. Ini berarti 1 buah gelombang memakan waktu $1 / 50$ detik $=0.02$ detik untuk terksekusi sepenuhnya. Waktu yang dibutuhkan 1 gelombang untuk tereksekusi seluruhnya biasa disebut Periode gelombang. Untuk lebih jelasnya lihat gambar berikut:

Gambar 2.1 Gambar sinusioda amplitudo 50 frekuensi $1 \mathrm{~Hz}$

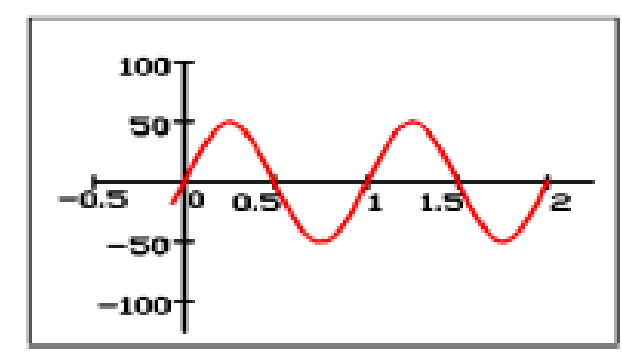

Domain $Y$ menggambarkan amplitudo, sedangkan domain $X$ menggambarkan waktu. Dari gambar diatas disimpulkan bahwa gelombang tersebut memiliki amplitudo 50 , frekuensi $1 \mathrm{~Hz}$ dan periode 1 detik. Amplitudo adalah nilai puncak / maksimum positif dari sebuah gelombang gelombang sinusoidal. Bila amplitudo suatu gelombang tertuliskan " 50 " maka 
nilai keluaran dari gelombang tersebut akan bergerak 0 ke 50 ke 0 ke 50 ke 0 dan 50 lagi, begitu seterusnya. Beda fasa adalah perbedaan sudut mulai antara 2 gelombang sinusoidal yang sedang diamati. Supaya lebih jelas perhatikan gambar dibawah ini:

\section{Gambar 2.2 gelombang sinus 50 sin ( wt )}

Gambar 2.3 gelombang sinus 50sin (wt45

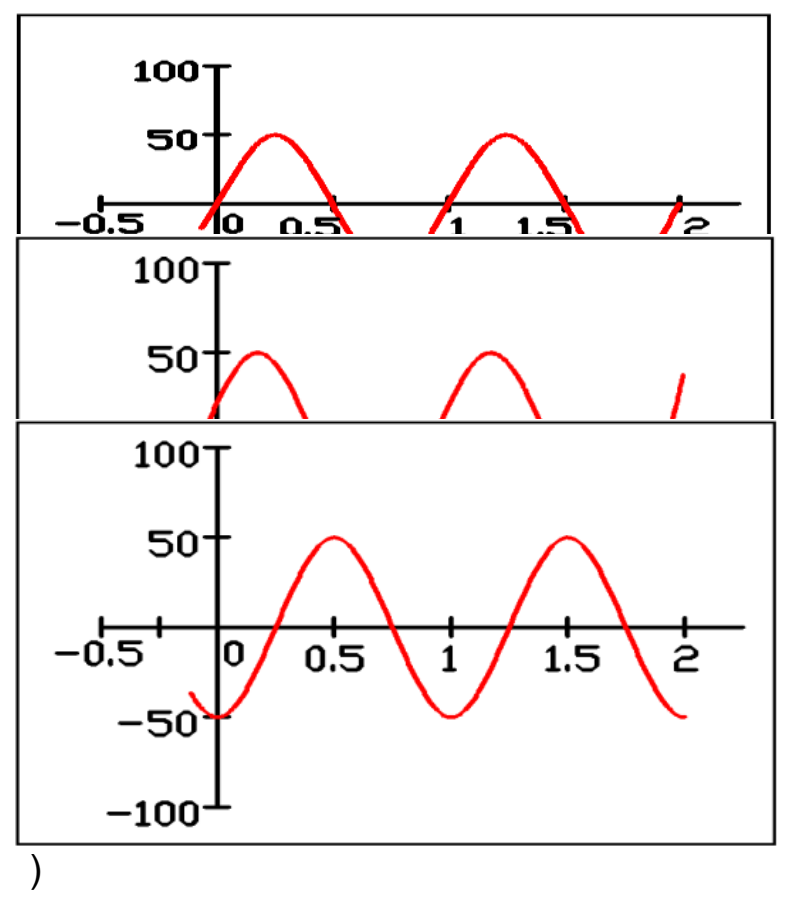

Gambar 2.4 gelombang sinus 50sin (wt90)

Perbedaan dari ketiga gambar diatas adalah sudut dalam memulai besaran nilainya. Jika gelombang pada gambar 3 memulai awalannya dari nilai sudut nol, maka gelombang pada gambar 4 memulai sudut 45 dan gelombang 5 memulainya dari sudut -90. Virtual instrument Virtual instrument adalah penggunaan perangkat lunak dan pengukuran modular perangkat keras yang bisa disesuaikan untuk menciptakan sistem pengukuran yang ditentukan sesuai keinginan pengguna. dan salah perangkat keras yang dapat mendukung akan virtual instrument adalah myDAQ dari National Instruments.

Gambar 2.5 spesifikasi NI myDAQ

NI MyDAQ adalah sebuah alat akuisisi data yang bisa membuat mahasiswa mampu untuk mengukur dan menganalisa sinyal langsung dimanapun dan kapan pun. NI MyDAQ itu compact dan portable sehingga mahasiswa dengan mudah membawanya untuk belajar atau
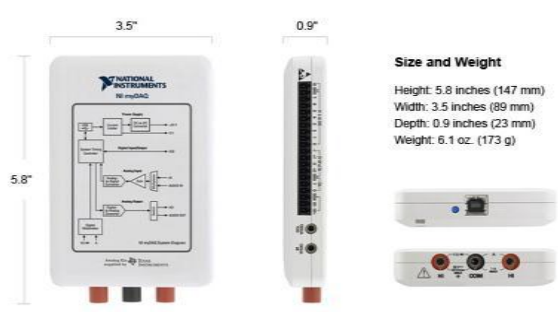

bereksperimen diluar ruangan secara lingkungan laboratorium dengan standar dan metode industri. NI MyDAQ ini sangat cocok untuk mahasiswa dan kalangan pelajar NI MyDAQ didalamnya terdapat dua masukan analog dan dua keluaran analog pada $200 \mathrm{KS} / \mathrm{s}$ dan 16 bit, yang mana memungkinkan untuk aplikasi seperti sampling sinyal audio. 8 masukan digital dan keluaran, dan juga menyediakan sumber tegangan untuk rangkaian sirkuit sederhana sebesar $+5 \mathrm{~V}$, +15V dan -15V. Dan $60 \mathrm{~V}$ DMM (Digital Multi Meter) untuk mengukur tegangan, arus, dan resistansi. NI myDAQ dibuat dengan standar dunia industri sehingga alat tersebut berkualitas baik. Sedangakan pada perangkat lunaknya menggunakan labVIEW.

Labview adalah perangkat lunak yang sangat ideal untuk setiap pengukuran atau sistem kontrol dan jantung dari platform desain NI. Mengintegrasikan semua alat yang insinyur dan ilmuwan perlukan untuk membangun atau membuat berbagai aplikasi dalam waktu yang sangat cepat. LabVIEW adalah sarana pengembangan 
untuk pemecahan masalah, percepatan produktivitas, dan inovasi terus-menerus. Adapun kegunaan LabVIEW bisa diberbagai aplikasi, seperti:
a. 1. Memperoleh data dan pemrosesan sinyal
b. 2. Pengendalian instrumen
c. 3. Pengujian otomatisasi dan validasi sistem
d. 4. Pemantauan dan pengendalian sistem

\section{LabView}

LabView adalah sebuah software yang menpunyai pemograman yang diproduksi oleh Nasional instrument dengan konsep yang berbeda. seperti bahasa pemograman lainnya yaitu $\mathrm{C}++_{+}$, Matlab dan Visual basic. LabView juga mempunyai beberapa fungsi dan peranan yang sama, perbedaannya bahwa LabView menggunakan bahasa pemograman berbasis grafis atau blok diagram sementara bahasa pemograman lainnya menggunakan bahasa text.

Program LabView dikenal dengan sebutan VI atau virtual instruments karena penampilan dan operasinya dapat meniru sebuah instruments. Pada LabView, user pertamatama membuat user interface atau front panel dengan menggunakan control dan indikator, yang dimaksud dengan kontrol adalah knobs, push buttons, dials dan peralatan input lainnya sedangkan yang dimaksud dengan indikator adalah grafik, led dan peralatan display lainnya. Setelah menyusun userinterface, lalu user menyusun blok diagram yang berisi kodekodeVls untuk mengontrol front panel. Software LabView terdiri dari tiga komponen utama yaitu:

\section{Front panel.}

Front panel adalah bagian window yang berlatar belakang belakang abu-abu serta mengandung control dan indiktor. Front panel digunakan untuk membangun sebuah VI, menjalankan program dan mendebug program.

Control dan functions pallete
Control dan functions pallete digunakan untuk membangun sebuah Vi. Control pallete merupakan tempat beberapa control dan indikator pada front panel, control palletehanya tersedia di front panel, untuk menampilkan contol pallete dapat dilakukan dengan mengklik windowsshow control pallete atau klik kanan pada front panel. Contoh control pallete dapat dilihat pada gambar dibawah ini

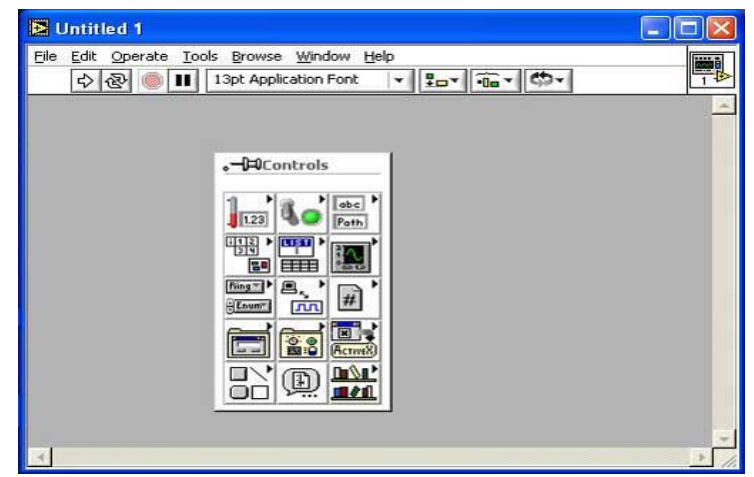

Gambar 2.7. Contol palette.

\section{METODOLOGI PENELITIAN.}

Dalam tahapan ini adalah tahapan terpenting supaya memberikan kemudahan dalam proses pembuatan alat dan pengambilan data. perancangan ini mempunyai tujuan supaya mendapatkan alat atau sistem yang baik seperti yang diharapkan, selain itu dengan adanya perancangan ini yang merupakan tahap penyelesaian Tugas Akhir, dilaksanakan secara sistematis dan saling berkaitan sehingga diperoleh peralatan dengan spesifikasi yang baik..

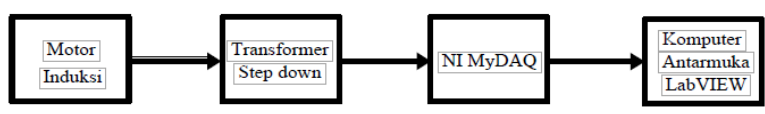

Langkah kerja dari diagram diatas antar lain, hubungkan antara kabel lilitan motor induksi ke transformer step down pada 
lilitan primer, kemudian hubungkan lilitan sekunder nya ke masukan analog my DAQ.kenapa menggunakan trafo step down, dikarenakan $\mathrm{NI}$ myDAQ hanya mempunyai rentang 2 untuk masukan analog sebesae $10 \mathrm{~V}$ sehingga perlu merubah tegangan dari motor induksi 3 fasa menjadi tegangan yang lebih kecil sehingga bisa dibaca dengan aman oleh NI myDAQ. kemudian hubungkan my DAQ ke pc/komputer supaya data yang masuk NI myDAQ bisa ditampilan dan diprogram untuk antarmukanya sesuai dengan keinginan keinginan kita.

Gambar 3.1 rangkaian pengukuran pola lissajous

Pada rangkaian pengukuran motor induksi 3 fasa menggunakan 2 buah trafo step down 220V/3V .pada kedua tegangan sekunder trafo step down dihubungkan ke masukan analog yang ada di myDAQ untuk dibaca nilai tegangannya dan frekuensinya. Dari dua sinyal yang diterima dari dua trafo tersebut maka akan dikombinasikan menjadi satu sehingga didapatkan pola lissajous. Pola lissajous tersebut akan didapatkan beda fasa antara kedua sinyal tersebut dan perbandingan frekuensi dan amplitudo. Selain pada motor induksi 3 fasa, pola lissajous dapat juga digunakan untuk analisa pada rangkaian R-L-C seri. Masing-masing komponen tersebut akan berpengaruh tehadap gelombang sinusiodal antara tegangan dan arus. sehingga akan diketahui komponen apakah yang akan membuat leading ( arus medahului tegangan ) atau lagging ( arus tertinggal tegangan ).

Gambar 4.2 rangkaian pengukuran pola lissajous pada rangkaian $\mathrm{R}-\mathrm{L}-\mathrm{C}$

\section{Alat dan Bahan}

Alat.
Untuk menunjang penelitian dan pengukuran, harus didukung dengan kelengkapan alat yang memadai seperti :

1. Digital Multi Meter (D.M.M).

Digital Multi Meter merk Hioki 3256-50, merupakan alat ukur yang telah mendapatkan setifikat dari badan Kalibrasi Nasional (KAN) dengan nomor sertifikat " Eb.0581.13. Digital Multi Meter Hioki 325650 sebagai bahan referensi alat ukur untuk pengukuran tegangan DC Power Supply, yang memiliki Correction pada tegangan $0,3998 \mathrm{~V}$ sebesar $+0.0002 \mathrm{~V}$, sedangkan pada tegangan $39,9 \mathrm{~V}$ sebesar $+0,10 \mathrm{~V}$. (Lembar kalibrasi dilampirkan).

\section{NI MyDAQ}

MyDAQ merupakan alat ukur yang dikeluarkan oleh National Instrument. Pada alat ukur MyDAQ mempunyai kelebihan di bandingkan dengan alat ukur diatas, dikarena hasil pengukuran dapat ditampilkan dikomputer dan disimpan dalam bentuk File.

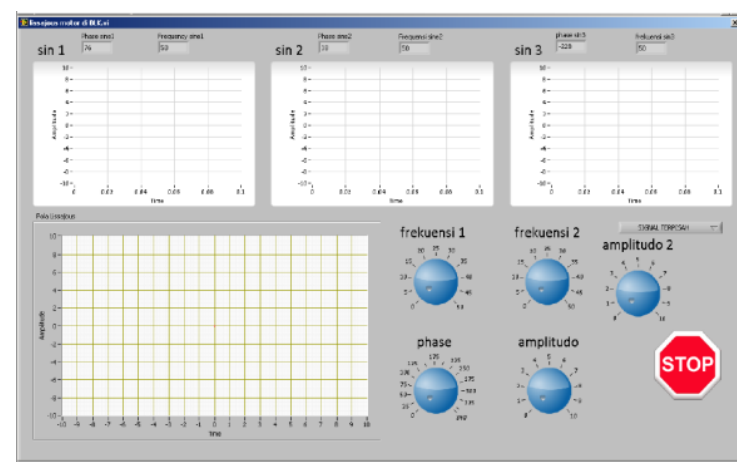

\section{Bahan Penelitian}

Pada penelitian ini, bahan yang digunakan untuk DC Power Supply 2 dioda dan DC Power Supply 4 dioda yaitu :
a. Transformator CT $500 \mathrm{~mA}$.
b. Transformator non CT $500 \mathrm{~mA}$.
c. Inductor $10 \mathrm{uH}$. 
d. kapasitor330uF/16V.

e. Resistor $3,3 \mathrm{k} \Omega$.

f. Papan Circuit Board (PCB).

\section{Rancangan Pengukuran.}

Rangkaian Pengukuran

Pada pengukuran kali ini yang akan dilakukan pengambilan data yaitu, rangkaian pengukuran motor induksi 3.

Berikut ini gambar rangkaian yang akan dilakukan pengukuran :

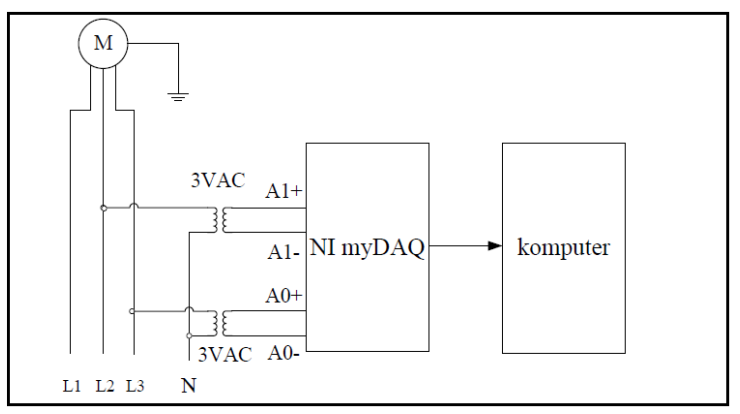

Gambar 3.2. Rangakaian pengukuran motor induksi

\subsubsection{Pemograman Antar Muka}

Untuk mempermudah dalam pengukuran suatu rangkaian penulis menggunakan software LabView dan alat akuisisi data yaitu NI MyDAQ, dengan desain antar muka pada komputer.

Berikut ini desain antar muka dengan komputer :

Gambar 3.3. Pemograman antarmuka

\section{HASIL DAN PEMBAHASAN}

\subsection{Hasil Pengukuran.}

HASIL PENGUKURAN PADA POLA LISSAJOUS PADA MOTOR 3 FASA
Gambar 4.1 pola lissajous dari tegangan motor induksi 3 fasa pada terminal $\mathrm{R}$ dan $\mathrm{S}$

Dari data diatas menunjukkan grafik dari pengukuran motor induksi 3 fasa dengan frekuensi $50 \mathrm{~Hz}$. SIN R pada gambar diatas adalah grafik sinus tegangan pada terminal L1 motor induksi 3 fasa. Untuk SIN S adalah grafik sinus tegangan dari

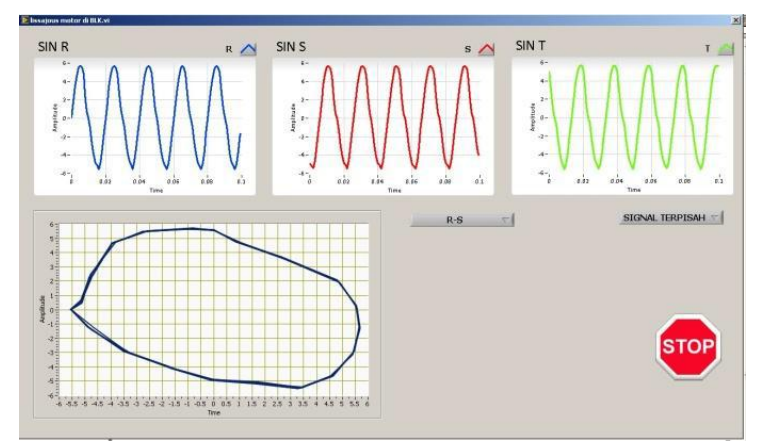

terminal L2 pada motor induksi 3 fasa. Sedangkan SIN T adalah grafik sinus tegangan dari terminal L3 pada motor induksi 3 fasa. Pola lissajous pada gambar diatas adalah hasil dari sinyal dari SIN $R$ dan SIN S yang menghasilkan sebuah lingkaran yang serong kiri. Karena pola lissaajous pada gambar 4.1 lingkaran serong kekiri maka untuk mengetahui beda fasa pada pola lissajous diatas maka menggunakan metode :

e. $\varnothing=180^{\circ}-\sin ^{-1}\left(\frac{B}{A}\right)=$
$180^{\circ}-\sin ^{-1}\left(\frac{22}{22,5}\right)=180^{\circ}-61,6^{\circ}=118,4^{\circ}$

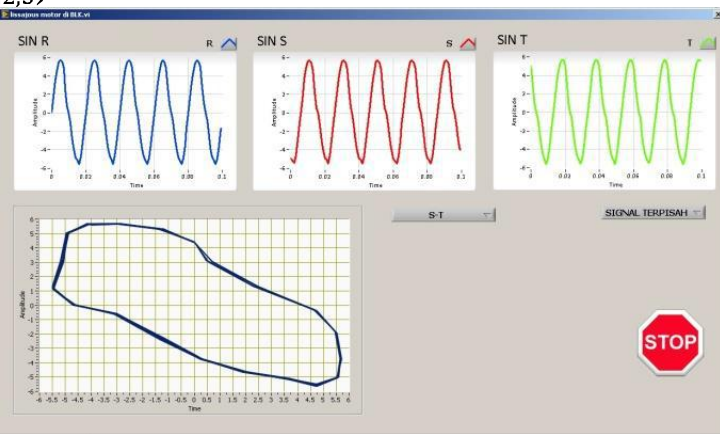

Dari metode diatas maka didapatkan perbedaaan fasa tegangan antara $R$ dan $S$ pada motor induksi 3 fasa adalah sebesar $118,4^{\circ}$.

Berikut adalah gambar pengukuran pola

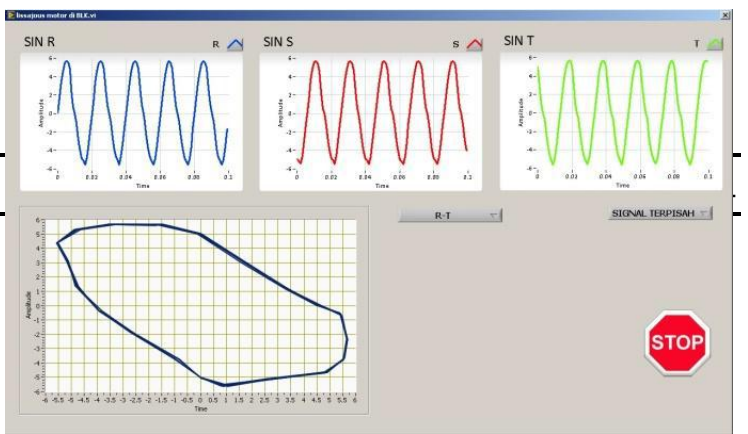


lissajous tegangan pada motor induksi 3 fasa pada terminal $\mathrm{R}$ dan $\mathrm{T}$.

Gambar 4.2 pola lissajous dari tegangan motor induksi 3 fasa pada terminal $\mathrm{R}$ dan $\mathrm{T}$

Pada gambar 4.2 menunjukkan grafik dari pengukuran tegangan motor induksi 3 fasa dengan frekuensi $50 \mathrm{~Hz}$. Pola lissajous pada gambar diatas adalah hasil dari sinyal dari SIN $R$ dan SIN $T$ yang menghasilkan sebuah lingkaran yang serong kiri. Karena pola lissaajous pada gambar 4.2 lingkaran serong kekiri maka untuk mengetahui beda fasa pada pola lissajous diatas maka menggunakan metode :

$\varnothing=180^{\circ}-\sin ^{-1}\left(\frac{B}{A}\right)=$

$180^{\circ}-\sin ^{-1}\left(\frac{17}{22,7}\right)=180^{\circ}-48,5^{\circ}=$ $131,5^{\circ}$

Dari metode diatas maka didapatkan perbedaaan fasa tegangan antara $R$ dan $T$ pada motor induksi 3 fasa adalah sebesar $131,5^{\circ}$. Berikut adalah gambar pengukuran pola lissajous tegangan pada motor Induksi 3 fasa pada terminal $S$ dan $\mathrm{T}$.

Gambar 4.3 pola lissajous dari tegangan motor induksi 3 fasa pada terminal $\mathrm{S}$ dan $\mathrm{T}$

Pada gambar 4.3 menunjukkan grafik dari pengukuran motor induksi 3 fasa dengan frekuensi $50 \mathrm{~Hz}$. Pola lissajous pada gambar diatas adalah hasil dari sinyal dari SIN $S$ dan SIN $T$ yang menghasilkan sebuah lingkaran yang serong kiri. Karena pola lissaajous pada gambar 10 lingkaran serong kekiri maka untuk mengetahui beda fasa pada pola lissajous diatas maka menggunakan metode :

$$
\begin{gathered}
\varnothing=180^{\circ}-\sin ^{-1}\left(\frac{B}{A}\right)= \\
180^{\circ}-\sin ^{-1}\left(\frac{17}{22,5}\right)=180^{\circ}-49,07^{\circ}=
\end{gathered}
$$

$130,93^{\circ}$

Dari metode diatas maka didapatkan perbedaaan fasa tegangan antara $S$ dan $T$ pada motor induksi 3 fasa adalah sebesar $130,93^{\circ}$.

\section{KESIMPULAN.}

Berdasarkan dari hasil pengukuran dan perhitungan maka dapat disimpulkan sebagai berikut:

1. Alat praktikum berkonsep virtual instrument yang dibuat adalah pola lissajous pada rangkaian R-L-C seri dan pada motor induksi 3 fasa dengan menggunakan alat akuisisi myDAQ dari National instrument.

2. untuk mengetahui beda fasa antar kedua sinyal dapat menggunakan pola lissajous, sedangkan untuk pembuktiannya dapat menggunakan metoda sebagai berikut :

- jika pola lissajous beebentuk lingakaran elips serong kekiri maka menggunakan rumus:

$$
\varnothing=180^{\circ}-\sin ^{-1}\left(\frac{B}{A}\right)
$$

- jika pola lissajous beebentuk lingakaran elips serong kekanan maka menggunakan rumus:

$$
\varnothing=\sin ^{-1}\left(\frac{B}{A}\right)
$$

3. Pada rangkaian seri $R-L-C$ bila $X L>$ dari XC maka arus akan tertinggal dari tegangan. Jika XL $<$ XC maka arus akan mendahului tegangan. Dan 
besarnya $\emptyset$ arus lagging dan leading

sebesar $\operatorname{arctg} \frac{X_{L}-X_{C}}{R}$

\section{UCAPAN TERIMAKASIH.}

Puji syukur saya ucapkan kepada Alloh yang maha esa atas selesainya penelitian ini, pada kesempatan ini penulis ingin mengucapkan terima kasih kepada:

1. Bapak DR.H.Dayat Hidayat, M.M selaku Rektor Universitas Pamulang.

2. Bapak IR.Dadang Kurnia, M.M selaku Dekan Fakultas Teknik Universitas Pamulang.

3. Bapak Syaiful Bakhri, S.T., M.Eng.Sc.,PhD. selaku Ketua Jurusan Teknik Elektro Universitas Pamulang dan pembimbing 1 yang dengan sabar dan senantiasa membimbing dan menyarankan penulisan Tugas Akhir ini.

\section{DAFTAR REFERENSI.}

[1] ibrahim KF. Teknik Digital. Andi Offset. Yogyakarta.1996.

[2] Zainal Abidin, Simulasi pengatur kecepatan motor induksi 1 fasa dengan matlab," ISSN 2502-0986.

[3] Sarjan Muhammad, 2002. Teori dan Modul Praktikum Motor Listrik Satu Fasa. Tadulako

[4] Muhammad Andang Novianta, Analisis Motor Induksi dengan Metode Cycloconveter berbasis mikrokontroler AT 89C51," ISSN: 1693-6930.

[5] Sarjan Muhammad, 2001. Bahan Ajar Perawatan dan Perbaikan Motormotor Listrik. TadulakoPalu..

[6] Akhyar Muchtar, Umar Muhammad, Prototipe Sistem Monitoring Penggunaan Daya Motor Listrik 3 Fasa Berbasis Java Programing, "ISSN 2338-6649". 